\title{
Exploring the Attitude of Greek Kindergarten and Primary School Teachers towards Inclusive Education
}

\author{
Maria Sakellariou' ${ }^{1}$, Panagiota Strati $^{2}$, Konsolas Emmanouil $^{3}$ \\ ${ }^{1}$ Department of Early Childhood Education, University of Ioannina, Greece. \\ ${ }^{2}$ Department of Early Childhood Education, University of Ioannina, Greece. \\ ${ }^{3}$ Department of Preschool Education Sciences and Educational Design, University of the Aegean, \\ Greece.
}

\begin{abstract}
ARTICLE INFO
Keywords:

inclusive education,

special educational

needs, disability, primary

school teachers,

kindergarten teachers

ABSTRACT

The present study was carried out during the school year 2014-2015 in the Region of Epirus with the participation of kindergarten teachers $(\mathrm{N}: 217)$ and primary school teachers $(\mathrm{N}: 303)$ and examines the attitude of Greek teachers towards the inclusion of children with special educational needs and/or disability in the general education classes. High-quality teaching in these classrooms is an essential factor for the successful participation of students in preschool and school education as well as for their transition to the next levels of school. The proper education of teaching staff and unified education constitute the objectives of the modern school system.
\end{abstract}

\section{Introduction}

Developing inclusive practices in teaching is an essential skill for teachers and those responsible for their education. The education community points out the need for pedagogical thinking to change from being functional for most students to getting everyone involved (Florian and BlackHawkins, 2011). For pedagogy to be effective, however, it needs to be inclusive and take all student needs and issues of their equality into consideration (Husbands and Pearce, 2012).

In 2012, the Hellenic Parliament ratified the United Nations Convention on the Rights of Persons with Disabilities (Law 4074, Government Gazette 88/Issue A'/11-04-2012) and-based on Article 24, paragraph 1-as a State Party, Greece "recognises the right of persons with disabilities to education... with a view to realising this right without discrimination and on the basis of equal opportunity... ensuring an inclusive education system at all levels and lifelong learning directed 
to: a) the full development of human potential and sense of dignity and self-worth, and the strengthening of respect for human rights, fundamental freedoms and human diversity; b) the development by persons with disabilities of their personality, talents and creativity, as well as their mental and physical abilities, to their fullest potential; c) enabling persons with disabilities to participate effectively in a free society".

Teaching in heterogeneous groups is not only a matter of understanding individual children's abilities and their educational needs so as to integrate them into the "typical" classroom with the children of their age, but also to adjust educational practices to different environments at different times (Ainscow et al., 2010; Rytivaara and Kershner, 2012). This requires fundamental changes in the way of thinking about children, study programmes, pedagogy and school organisation (Slee, 2011). In order to implement an inclusive system of education, teachers need to be equipped not only with competencies but also with the necessary values and beliefs to respond to the needs of different students and to the development of equitable systems of education (Engelbrecht, 2013). The adequacy of teachers is about attitudes, knowledge and skills.

The aim of this study is to evaluate the views of kindergarten and primary school teachers that show their attitudes towards inclusive education, while also taking into account the factor of their varying knowledge of special education practices. The participants were asked if they agree with the following statements:

- Students with disabilities should participate in activities together with their fellow students with no disability.

- Students with no disability accept their peers with special educational needs in the general class.

- The teaching staff has the knowledge, skills and experience to teach students with disabilities in their classes.

- The structures of general and special education and the scientific personnel need to cooperate for the full integration of students into the general school.

- Inclusion fosters the true friendship between students with and without disabilities.

\section{Models of Inclusive Education}

Different models of inclusion have been recorded in the Greek education system and international literature (McLeskey and Waldron \& Redd, 2012; Norwich, 2000; Strati, 2017). Nevertheless, four of these models are considered the most fundamental:

The first model of full inclusion (called full non-exclusionary inclusion) is characterised by the equal participation of all children at school. It is against any kind of discrimination and focuses on the interaction of all children in the school environment, regardless of their specificities. In full inclusion, children with special educational needs do not receive any support or special education, since the educational environment of the class is regarded as the most appropriate for all children. No separate institutional and legal frameworks exist for children with disabilities.

The second model of participation in the same class (called focus on participating in same place) is characterised by the provision of support by a special education teacher inside and outside the inclusive class or in a space specifically designed for that purpose.

The third model of focus on individual needs emphasises the evaluation of children's special educational needs. When children have serious difficulties and are unable to follow the general education programme, they are recommended to attend a special school for a specific period of time. 
The fourth model of choice-limited inclusion recognises that education in special schools is helpful for children with special needs, especially in relation to their academic progress. Moreover, it recognises that children with special needs should be able to attend general education since their interaction with children without disability helps them to socialise.

\section{Methodology}

\subsection{Study Sample}

A random sample of 520 teachers was used for the purposes of this study. The sample comprises 217 kindergarten teachers and 303 teachers from the Region of Epirus during the school year 20142015. The teaching staff that participated in the study and answered the questionnaires was selected by random sampling. In the beginning, we recorded how many teachers serve in each kindergarten or primary school in the four prefectures of the Region of Epirus. Our objective was to select a large percentage of the total population of teachers in Epirus (at least 20 per cent). We employed the method of stratified random sampling and divided teaching staff into two subgroups (strata), kindergarten and primary school teachers (Zafeiropoulos, 2013; Karageorgos, 2001). The study was carried out between October 2014 and March 2015.

\subsection{Demographic Characteristics of the Teachers of the Study Population}

\subsubsection{Teaching experience}

As far as the years of teaching experience are concerned, $43.8 \%$ of teachers have 11 to 20 years of experience, $22.9 \%$ have 21 to 30 years of experience, $18.3 \%$ have 6 to 10 years and $10.8 \%$ have up to five years of experience, while there is a mere $4.2 \%$ with more than 30 years of experience (Table 1).

\begin{tabular}{|c|c|c|}
\hline \multirow{4}{*}{$\begin{array}{c}\text { Years } \\
\text { of } \\
\text { teaching } \\
\text { experience }\end{array}$} & Up to 5 years & $10.8 \%$ \\
\cline { 2 - 3 } & 6 to 10 years & $18.3 \%$ \\
\cline { 2 - 3 } & 11 to 20 years & $43.8 \%$ \\
\cline { 2 - 3 } & More than 30 years 30 years & $22.9 \%$ \\
\cline { 2 - 3 } & $4.2 \%$ \\
\hline
\end{tabular}

Table 1: Distribution of teachers according to their years of teaching experience.

\subsubsection{Level of education}

The largest share (44.2\%) of teachers do not have another degree beyond their basic studies, while $22.7 \%$ have taken a two-year course of further training in teaching at a Teachers' College of Primary Education (Didaskaleio) and 13.3\% have completed an Academic and Professional 
Upgrading Programme. 9.0\% hold a second degree from a higher education institution (AEI) or technological education institute (TEI), $8.5 \%$ have a postgraduate diploma, $1.5 \%$ a doctorate $(\mathrm{PhD})$ and a small percentage $(0.8 \%)$ have completed a Pedagogical Training Program (EPPAIK, School of Pedagogical and Technological Education-ASPETE).

\subsubsection{Special education knowledge}

Among the (N: 520) kindergarten and primary school teachers that participated in our study, the majority of $57.0 \%(\mathrm{~N}: 297)$ have little knowledge concerning children with special educational and disabilities. $17.0 \%(\mathrm{~N}: 91)$ have adequate knowledge, $14.0 \%(\mathrm{~N}: 71)$ no knowledge, $12.0 \%$ (N: 61) good knowledge, while no teacher $(0.0 \%$ or $\mathrm{N}: 0)$ evaluates his/her knowledge as excellent (Graph 1).

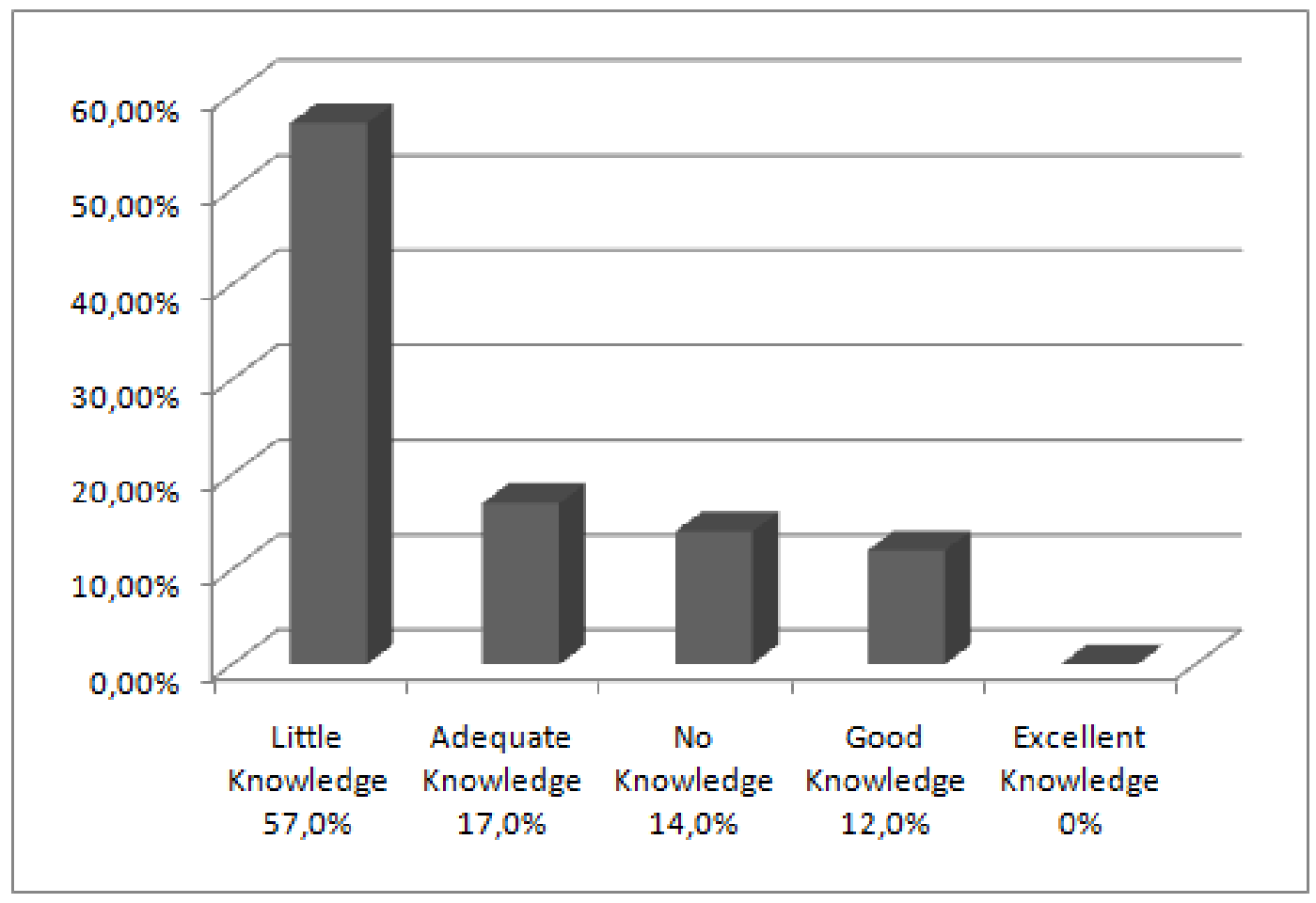

Graph 1: Distribution of teachers according to their knowledge in special education.

\subsection{Research tool}

Questionnaire survey: The survey research through questionnaires was deemed the most appropriate method for the collection of data regarding the views of a representative sample of kindergarten and primary school teachers on issues of inclusion and integration of children with special educational needs into the general class. Based on an in-depth study of relevant literature, a questionnaire was formulated with "open-" and "closed-ended" questions. 


\subsection{Limitations of the study}

Prior to the onset of the study, it was decided that participating teachers would have to work at public kindergartens and primary schools in the Region of Epirus. We are persuaded that further research at the national level is needed in order to generalise our findings more securely.

\subsection{Data analysis}

The answers to the questionnaires were collected, coded and processed with the help of the SPSS 18 statistical analysis package and, where appropriate, analysed.

Pearson chi square test. To evaluate the potential relationship between two qualitative variables, the $\chi^{2}$ independence test was employed, with the use of the Pearson asymptotic control to calculate the level of importance $\mathrm{p}$ based on the absolute frequency of observed responses. We reject our initial hypothesis concerning the level of importance a (usually $0,05=5 \%$ ). The statistical package calculates the $\chi^{2}$ value and the probability $\mathrm{p}$ of the hypothesis. Apparently, our initial hypothesis will be rejected for small values of $p$ (large $\chi^{2}$ value), smaller than 0,05 , in other words values of $p>0,05$ or $p<0,05$. Moreover, degrees of freedom are provided (df). In conclusion, if $p>0,05$ we shall consider that responses do not have a statistical deviation on the level of importance, whereas if $\mathrm{p}<0,05$ no deviation exists.

ANOVA was used in the question related to teachers' attitude towards inclusive education, by examining the variable of kindergarten and primary school teachers' knowledge in special education. The evaluation was based on descriptive statistics. This is an analysis of variance. If no statistical deviation exists among groups, the estimated variance will be approximately equal to the variance outside the groups (overall), otherwise variance outside the groups will be much larger. Thus, we examine the ratio of the two variances and get an F value, this statistical indicator follows a specific distribution Fn, $\mathrm{k}$ and we reject the hypothesis for large values of $\mathrm{F}$ equivalent to $\mathrm{p}<0,05$. This control was carried out using the $\chi^{2}$ criterion too, given the small number of groups (Lioki-Leivada and Anagnostopoulos, 2004).

\section{Presentation of the Study Results}

In this section, the findings of our study are presented, regarding the views of teachers on integrating students with disabilities and special educational needs into the general classes of education and-more specifically-the teachers' attitude towards inclusive education.

\subsection{Questions: Please evaluate the following views that show the attitude of teachers towards inclusive education, on a scale of 1-5 where:}

1: Strongly disagree/ 2: Disagree/ 3: Neither agree nor disagree/ 4: Agree/ 5: Strongly agree

\subsubsection{Should students with disabilities participate in classroom activities together with their peers with no disability?}

All teachers agree and strongly agree that children with disabilities and special educational needs should participate in activities together with their fellow students. More specifically, $45.2 \%$ of kindergarten teachers agree and $37.8 \%$ strongly agree, while $41.9 \%$ of primary school teachers 
agree and $39.6 \%$ strongly agree. A small percentage of teachers are neutral, whereas we have to point out that there is no kindergarten teacher who strongly disagrees. The above results are confirmed by the measurement using the chi square method where $\chi^{2}=6,412 \mathrm{a}$, $\mathrm{df}=4$ and $\mathrm{p}=$ 0,170 . The Pearson chi square test shows that no significant statistical dispersion exists between the answers of kindergarten and primary school teachers.

\section{Crosstab}

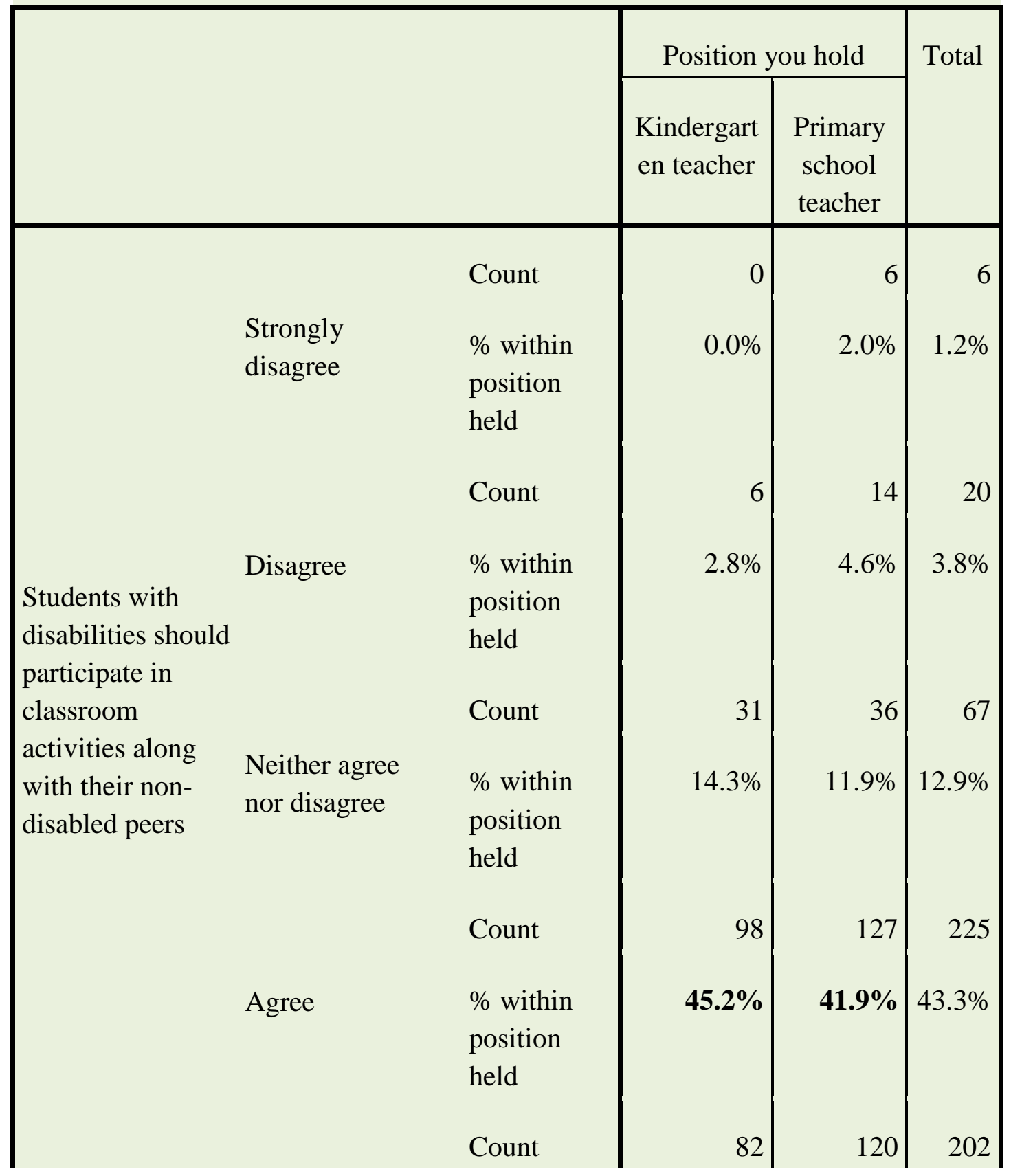




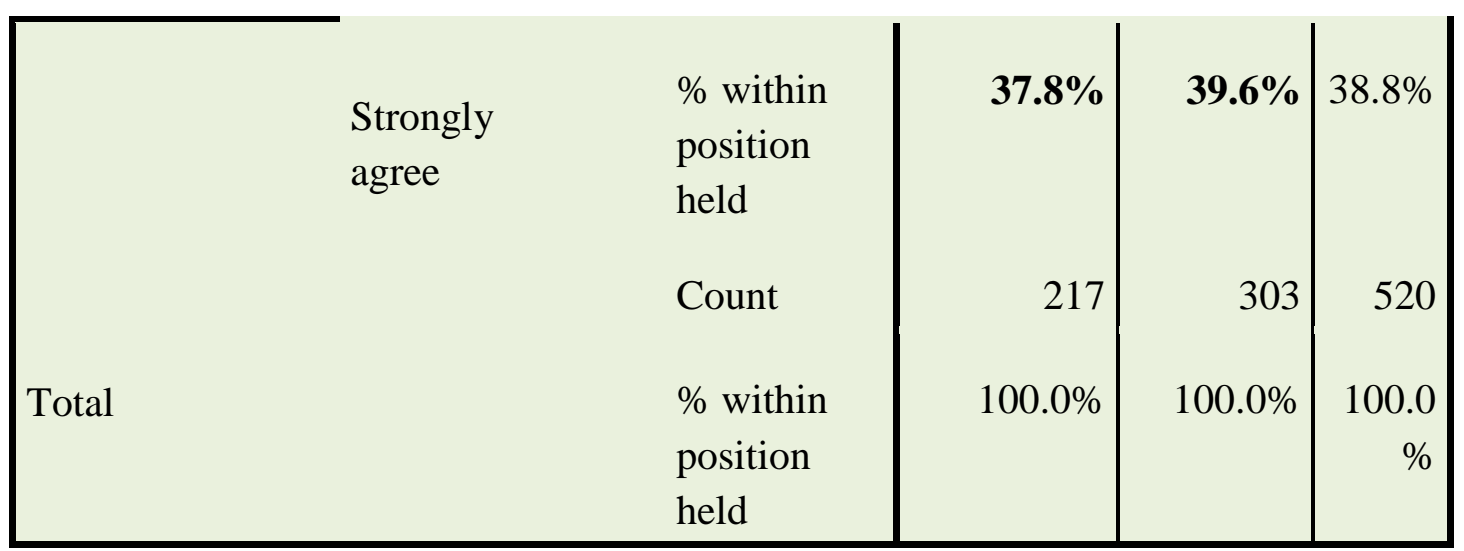

Table 2: Total quantitative results for the category: "Common Activities".

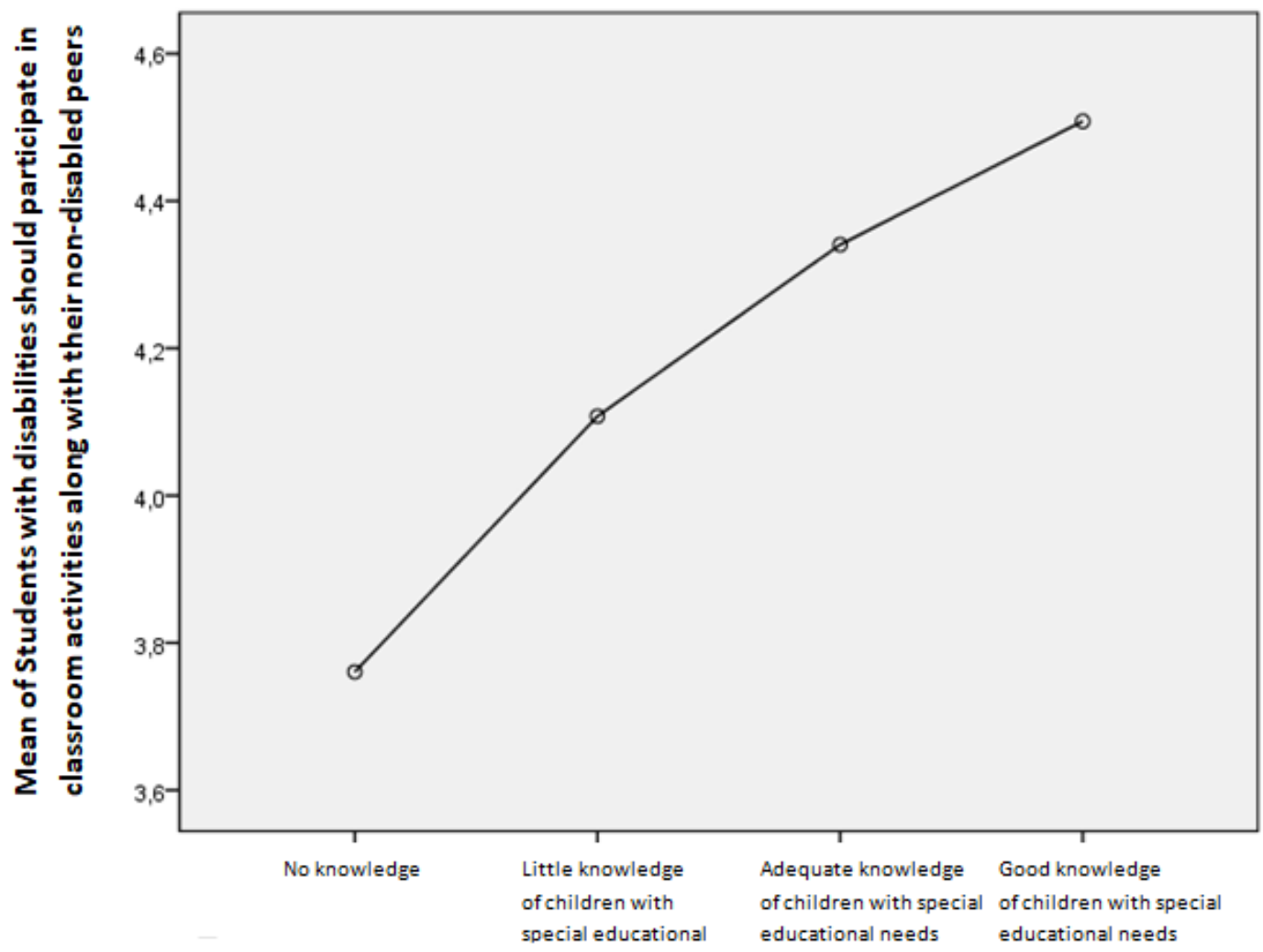

Please evaluate your knowledge in children with special educational needs on a scale of 1-5

Graph 2: Distribution of groups according to teachers' knowledge in special education: Common activities.

The examination of the variable of knowledge in special education (Graph 2) in relation to the view on common activities for all children reveals that teachers with good knowledge of children with special educational needs agree and strongly agree (N:61, mean 4,51), teachers with adequate knowledge of children with special educational needs agree and strongly agree (N:91, mean 4,34), 
teachers with little knowledge of children with disabilities agree (N:297, mean 4,11), while teachers with no knowledge in special education neither agree nor disagree (N:71, mean 3,76). Descriptive statistics were used for the evaluation. According to the ANOVA analysis of variance, a significant statistical variability is observed in teachers' answers $(\mathrm{F} 3,516=10,451, \mathrm{P}=0,000)$.

\subsubsection{Do non-disabled students accept their peers with special educational needs and disabilities in the general class?}

\section{Crosstab}

\begin{tabular}{|c|c|c|c|c|c|}
\hline & & & Position y & ou hold & Total \\
\hline & & & $\begin{array}{l}\text { Kindergart } \\
\text { en teacher }\end{array}$ & $\begin{array}{l}\text { Primary } \\
\text { school } \\
\text { teacher }\end{array}$ & \\
\hline & & Count & 10 & 6 & 16 \\
\hline & $\begin{array}{l}\text { Strongly } \\
\text { disagree }\end{array}$ & $\%$ within & $4.6 \%$ & $2.0 \%$ & $3.1 \%$ \\
\hline & & position held & & & \\
\hline & & Count & 25 & 66 & 91 \\
\hline Non-disabled & Disagree & $\%$ within & $11.5 \%$ & $21.8 \%$ & $17.5 \%$ \\
\hline their peers with & & posituon nela & & & \\
\hline educational needs & & Count & 81 & 108 & 189 \\
\hline $\begin{array}{l}\text { in the general } \\
\text { class of education }\end{array}$ & $\begin{array}{l}\text { Neither agree } \\
\text { nor disagree }\end{array}$ & $\%$ within & $37.3 \%$ & $35.6 \%$ & $36.3 \%$ \\
\hline & & position held & & & \\
\hline & & Count & 80 & 103 & 183 \\
\hline & Agree & $\%$ within & $36.9 \%$ & $34.0 \%$ & $35.2 \%$ \\
\hline & & position held & & & \\
\hline & & Count & 21 & 20 & 41 \\
\hline & $\begin{array}{l}\text { Strongly } \\
\text { agree }\end{array}$ & $\begin{array}{l}\% \text { within } \\
\text { position held }\end{array}$ & $9.7 \%$ & $6.6 \%$ & $7.9 \%$ \\
\hline Total & & Count & 217 & 303 & 520 \\
\hline
\end{tabular}




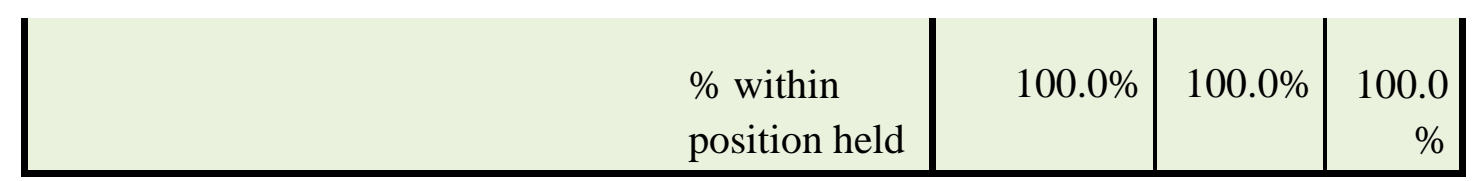

Table 3: Total quantitative results for the category: "Acceptance in the General Class".

Analysing the results as to the position that participants hold, we find that kindergarten (37.3\%) and primary school teachers $(35.6 \%)$ neither agree nor disagree as they are hesitant about the view that non-disabled students accept their peers with special educational needs in the general class. The examination of the Pearson chi square test reveals a significant statistical dispersion $(\mathrm{p}=$ 0,015 ), since $21.8 \%$ of primary school teachers disagree compared to $11.5 \%$ of kindergarten teachers. These results are confirmed by the chi square method of measurement where $\chi^{2}=$ $12,360 \mathrm{a}, \mathrm{df}=4$ and $\mathrm{p}=0,015$.

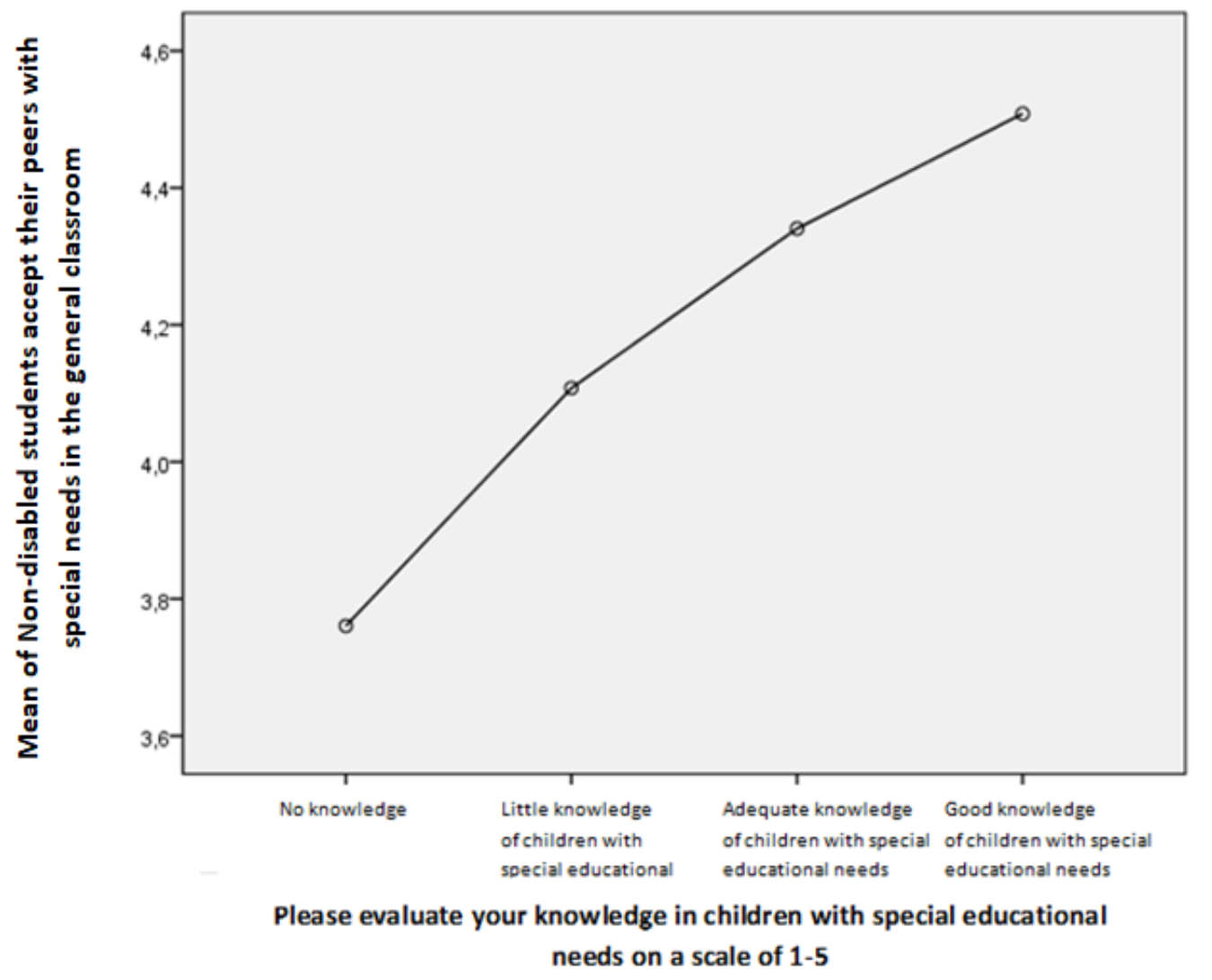

Graph 3: Distribution of groups according to teachers' knowledge in special education: Acceptance in the general class.

As far as teachers' views are concerned in relation to the variable describing their knowledge in special education, the above chart reveals that those with good knowledge of children with special educational needs (N:61, mean 3,07) neither agree nor disagree, while the same is also true for those with adequate knowledge (N:91, mean 3,11). But teachers with little (N:297, mean 3,36) or no knowledge (N:71, mean 3,31) tend to agree that non-disabled students accept their peers with 
disabilities. This evaluation was carried out using descriptive statistics. According to the ANOVA analysis of variance there is significant statistical deviation between the teachers' responses $(\mathrm{F} 3,516=2,728, \mathrm{P}=0,043)$.

\subsubsection{Do primary school teachers have the knowledge, skills and experience to teach students with disabilities in their classrooms?}

The analysis of the above table indicates that primary school teachers do not have the knowledge, skills and experience to teach students with disabilities in their classrooms. 54.8\% of kindergarten teachers disagree and $15.7 \%$ strongly disagree, while $51.2 \%$ of primary school teachers disagree and $22.4 \%$ strongly disagree. The Pearson chi square test reveals a significant statistical deviation $(\mathrm{p}=0,002)$. This deviation is related to the largest share of primary school teachers who strongly disagree in contrast to kindergarten teachers. A small percentage $(4.1 \%)$ of kindergarten teachers strongly agree that teachers have the necessary knowledge, skills and experience, whereas no primary school teacher $(0.0 \%)$ agrees strongly with this statement. These results are confirmed by the measurement using the chi square method, where $\chi^{2}=16,637 \mathrm{a}, \mathrm{df}=4$ and $\mathrm{p}=0,002$.

\section{Crosstab}

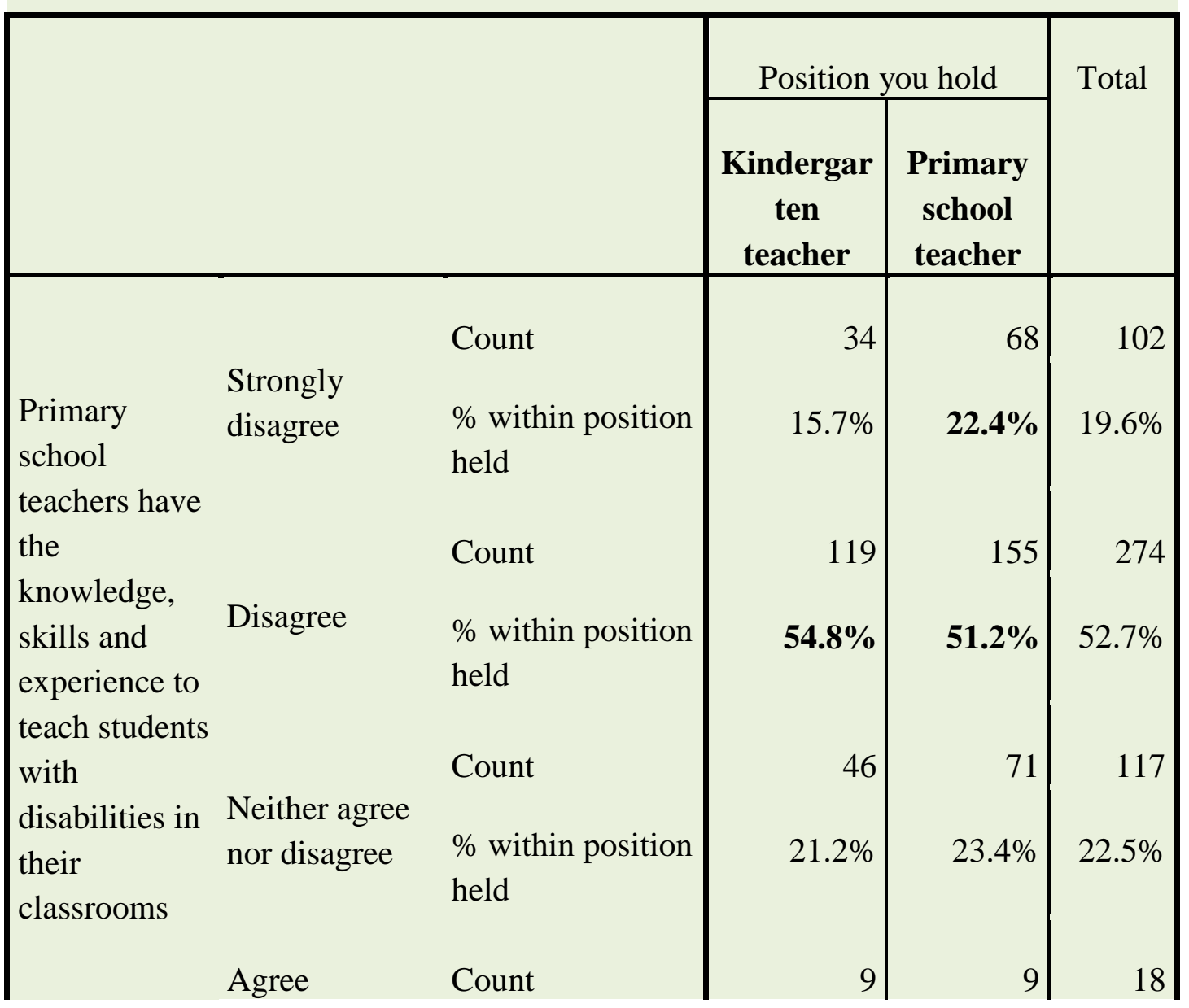




\begin{tabular}{|c|c|c|c|c|c|}
\hline & & $\begin{array}{l}\% \text { within position } \\
\text { held }\end{array}$ & $4.1 \%$ & $3.0 \%$ & $3.5 \%$ \\
\hline & & Count & 9 & 0 & 9 \\
\hline & $\begin{array}{l}\text { Strongiy } \\
\text { agree }\end{array}$ & $\begin{array}{l}\% \text { within position } \\
\text { held }\end{array}$ & $4.1 \%$ & $0.0 \%$ & $1.7 \%$ \\
\hline & & Count & 217 & 303 & 520 \\
\hline Total & & $\begin{array}{l}\% \text { within position } \\
\text { held }\end{array}$ & $100.0 \%$ & $100.0 \%$ & $100.0 \%$ \\
\hline
\end{tabular}

Table 4: Total quantitative results for the category: “Teachers' Knowledge, Skills and Experience”.

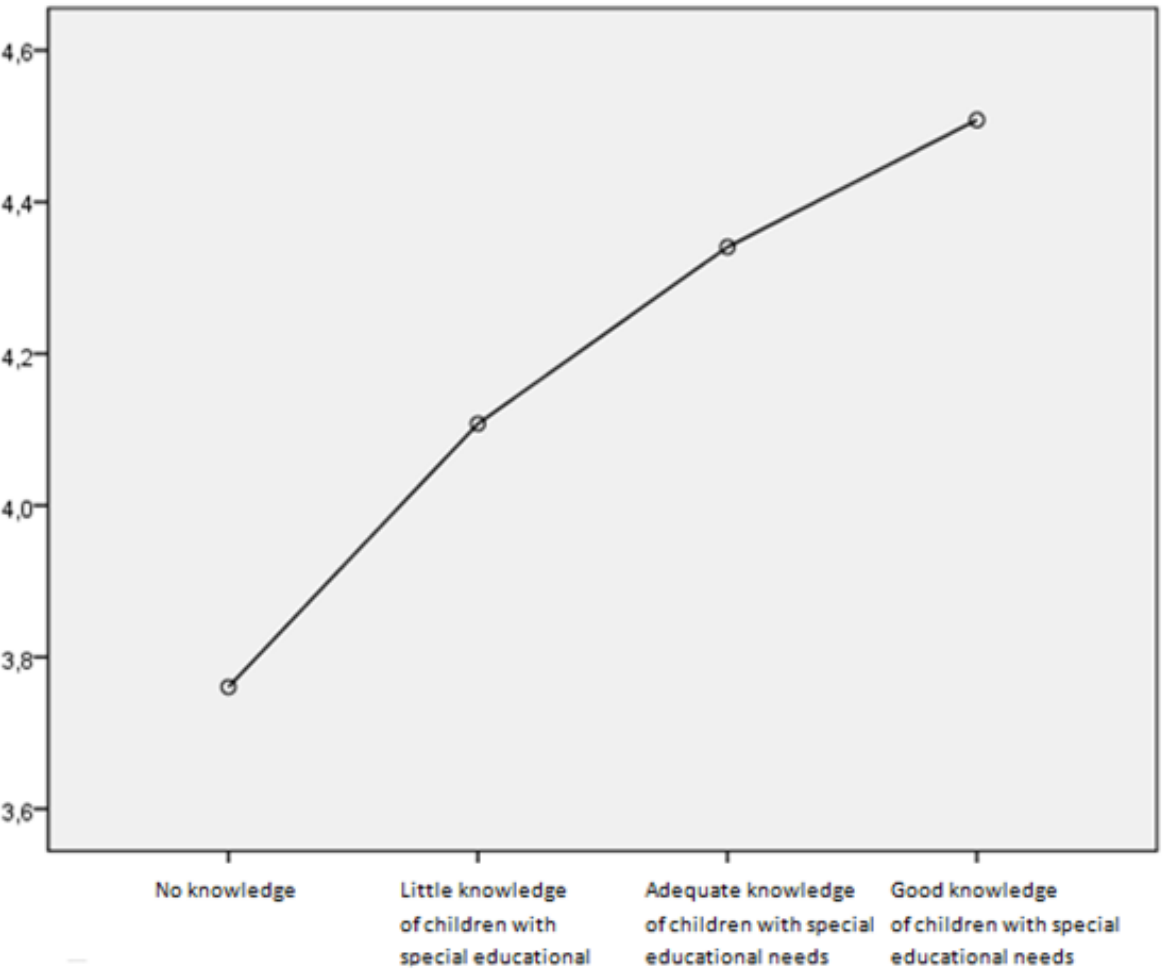

Please evaluate your knowledge in children with special educational

needs on a scale of 1-5 
Graph 4: Distribution of groups according to teachers' knowledge in special education: Teachers' knowledge, skills and experience.

Teachers with no knowledge in children with special educational needs strongly disagree (N:71, mean 1,89), those with little (N:297, mean 2,18) and adequate knowledge disagree (N:91, mean 2,14), while teachers with good knowledge (N:61, mean 2,34) neither agree nor disagree that primary education teachers have the knowledge, skills and experience to teach children with disabilities in their classrooms. The evaluation was done using descriptive statistics. According to the ANOVA analysis of variance there is significant statistical deviation between teachers' responses $(\mathrm{F} 3,516=3,603, \mathrm{P}=0,013)$.

\subsubsection{Is cooperation between special and general education structures and scientific personnel necessary for the full inclusion of students into the general school?}

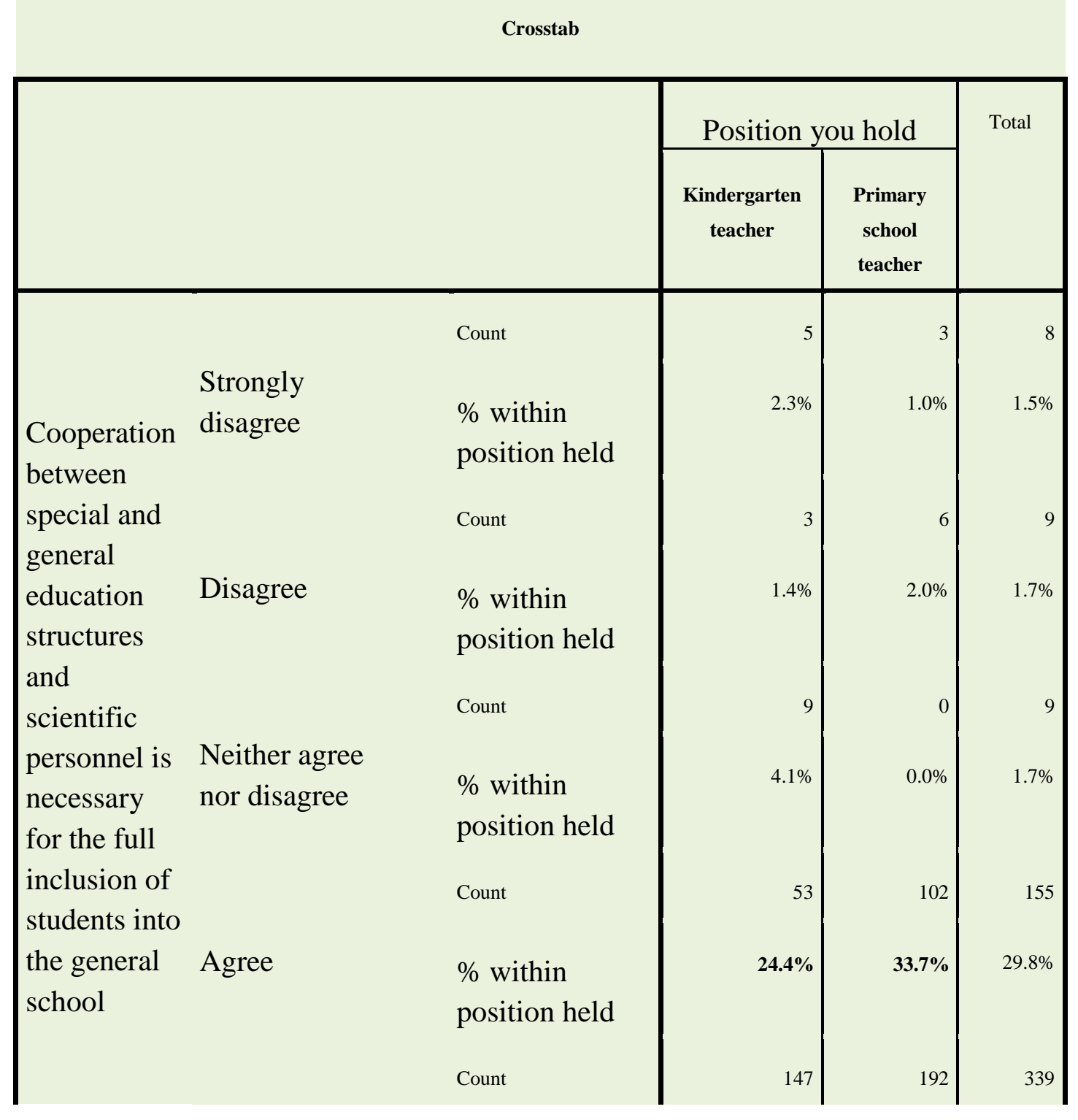




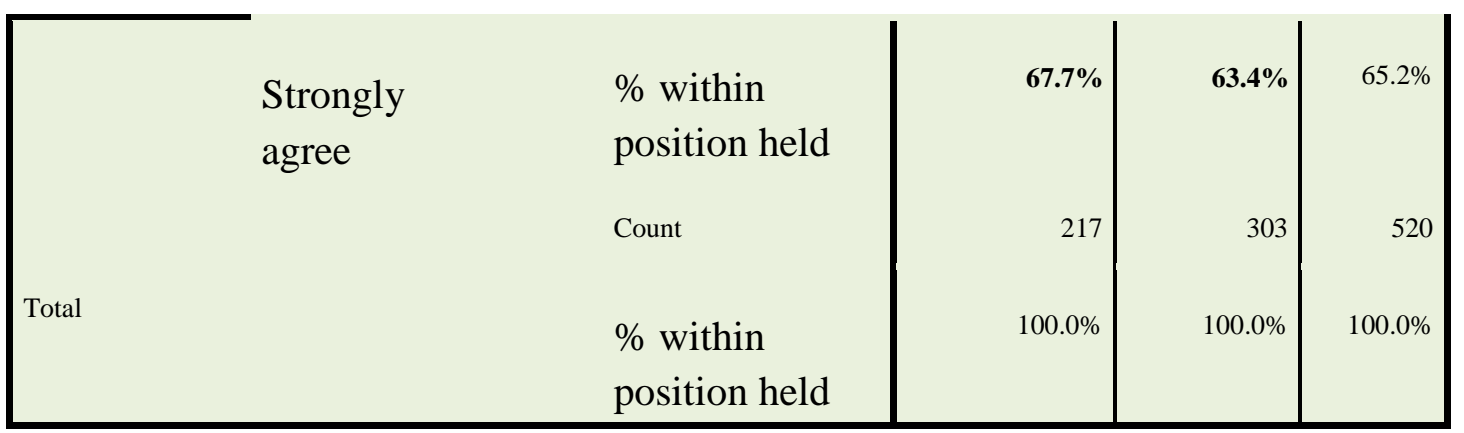

Table 5: Total quantitative results for the category: "Cooperation on Inclusion".

Kindergarten and primary school teachers strongly agree that the cooperation between special and general education structures and the scientific personnel is necessary for the full inclusion of students into the general school. The above results are confirmed by the chi square calculation, where $\chi^{2}=18,240 \mathrm{a}$, df $=4$ and $\mathrm{p}=0,001$. More specifically, 67.7\% of kindergarten teachers strongly agree and $24.4 \%$ agree, while $63.4 \%$ of primary school teachers strongly agree and $33.7 \%$ agree. On the other hand, only a small percentage of teachers have a different opinion. The Pearson chi square test shows a significant deviation $(\mathrm{p}=0,001)$, which is related to the percentage of kindergarten teachers who neither agree nor disagree in contrast to the relevant $0.0 \%$ of primary school teachers. The findings are confirmed by the chi square calculation, where $\chi^{2}=18,240 \mathrm{a}$, df $=4$ and $\mathrm{p}=0,001$.

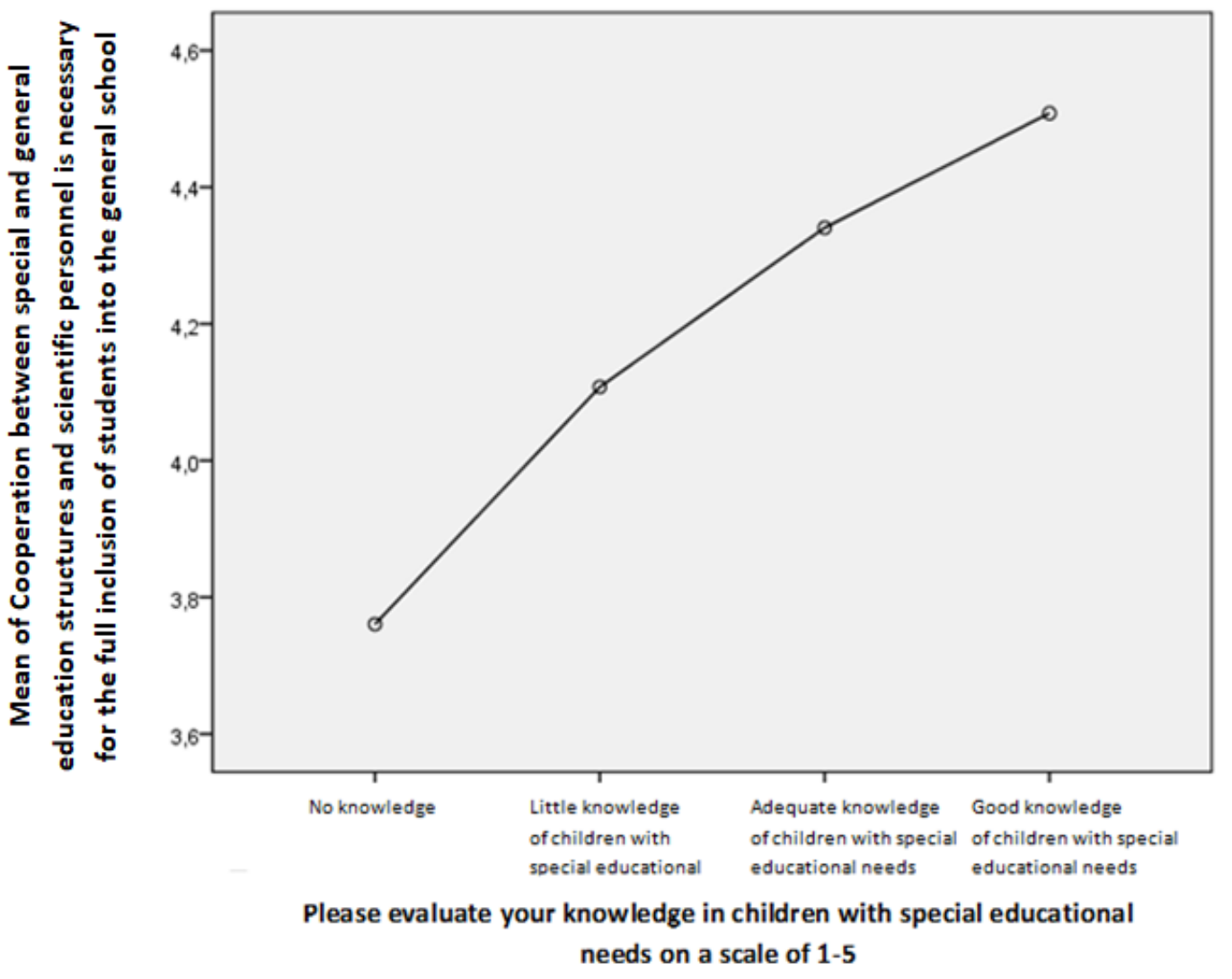


Graph 5: Distribution of groups according to teachers' knowledge in special education: Cooperation in the context of inclusion.

The evaluation-based on descriptive statistics-of the variable related to the knowledge of teachers in special education shows that all teachers agree on the necessity of cooperation between structures and personnel, regardless of their knowledge. Of course, those with good knowledge strongly agree $(\mathrm{N}: 61$, mean 4,74$)$ and this is made obvious from the above graph. Teachers with no knowledge $(\mathrm{N}: 71$, mean 4,51), little $(\mathrm{N}: 297$, mean 4,54) or adequate knowledge (N:91, mean $4,52)$ either agree or strongly agree. According to the ANOVA analysis of variance there is no significant statistical deviation between the responses of teachers $(F 3,516=1,411, P=0,239)$.

\subsubsection{Does inclusion foster true friendship between students with and without disability?}

Primary school and kindergarten teachers agree and strongly agree that inclusion fosters true friendship between students with and without disabilities. In particular, $49.3 \%$ of kindergarten teachers agree and $42.9 \%$ strongly agree, while $35.6 \%$ of primary school teachers agree and $53.1 \%$ strongly agree. A small percentage of teachers are neutral or have the opposite view. The above results are confirmed by the measurement using the chi square method where $\chi^{2}=10,412 \mathrm{a}$, $\mathrm{df}=4$ and $\mathrm{p}=0,034$. The Pearson chi square test shows a significant deviation $(\mathrm{p}=0,034)$, which is related to the higher percentage of primary school teachers who strongly agree as opposed to the higher percentage of kindergarten teachers who agree.

\section{Crosstab}

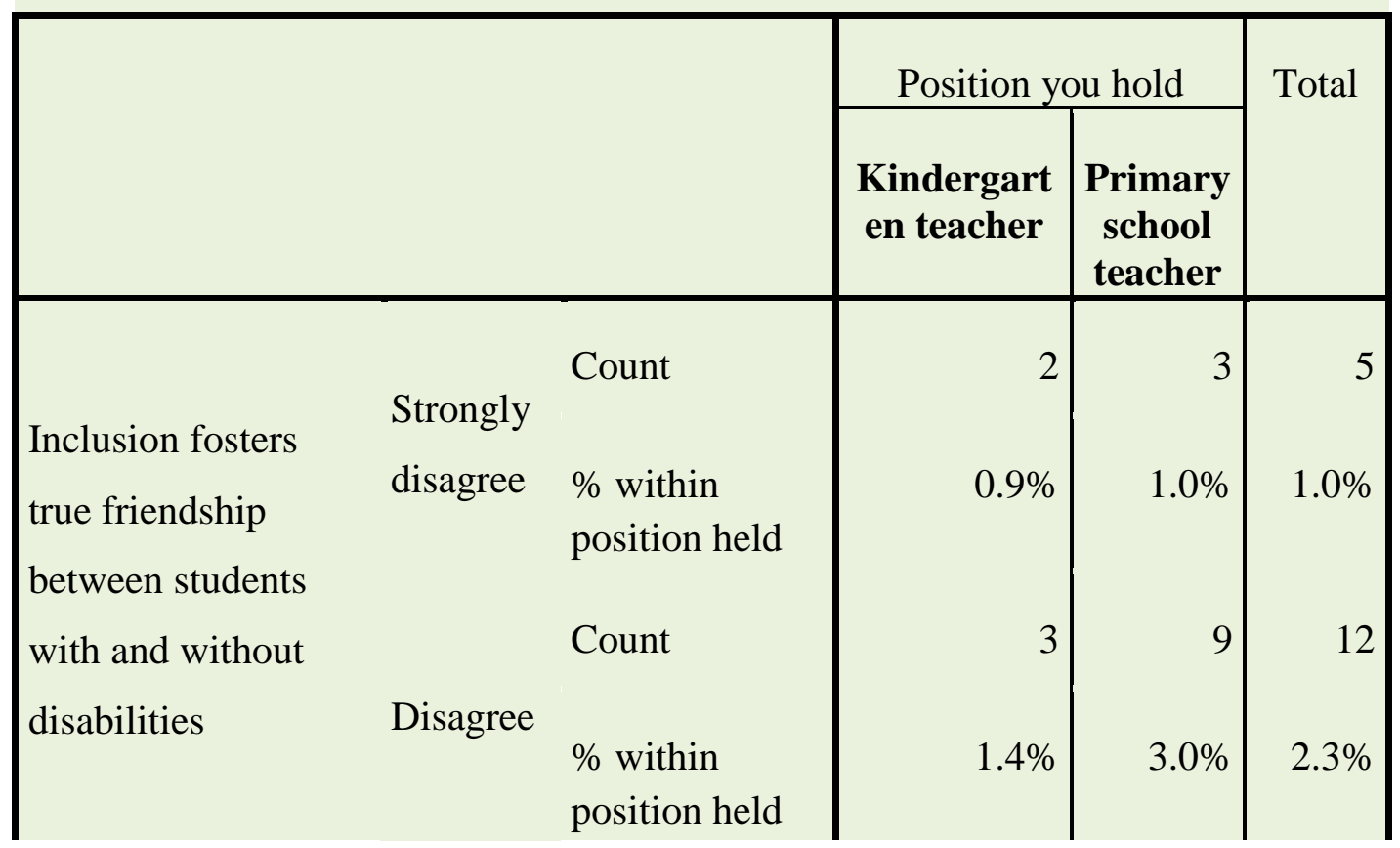




\begin{tabular}{|c|c|c|c|c|c|}
\hline & $\begin{array}{l}\text { Neither } \\
\text { agree } \\
\text { nor } \\
\text { disagree }\end{array}$ & $\begin{array}{l}\text { Count } \\
\% \text { within } \\
\text { position held }\end{array}$ & $\begin{array}{r}12 \\
5.5 \%\end{array}$ & $\begin{array}{r}22 \\
7.3 \%\end{array}$ & $\begin{array}{r}34 \\
6.5 \%\end{array}$ \\
\hline & & Count & 107 & 108 & 215 \\
\hline & Agree & $\begin{array}{l}\% \text { within } \\
\text { position held }\end{array}$ & $49.3 \%$ & $35.6 \%$ & $41.3 \%$ \\
\hline & Strongly & & 93 & 161 & 254 \\
\hline & agree & $\begin{array}{l}\% \text { within } \\
\text { position held }\end{array}$ & $42.9 \%$ & $53.1 \%$ & $48.8 \%$ \\
\hline & & Count & 217 & 303 & 520 \\
\hline Total & & $\begin{array}{l}\% \text { within } \\
\text { position held }\end{array}$ & $100.0 \%$ & $100.0 \%$ & $\begin{array}{r}100.0 \\
\%\end{array}$ \\
\hline
\end{tabular}

Table 6: Total quantitative results for the category: "Inclusion and friendship between students". 


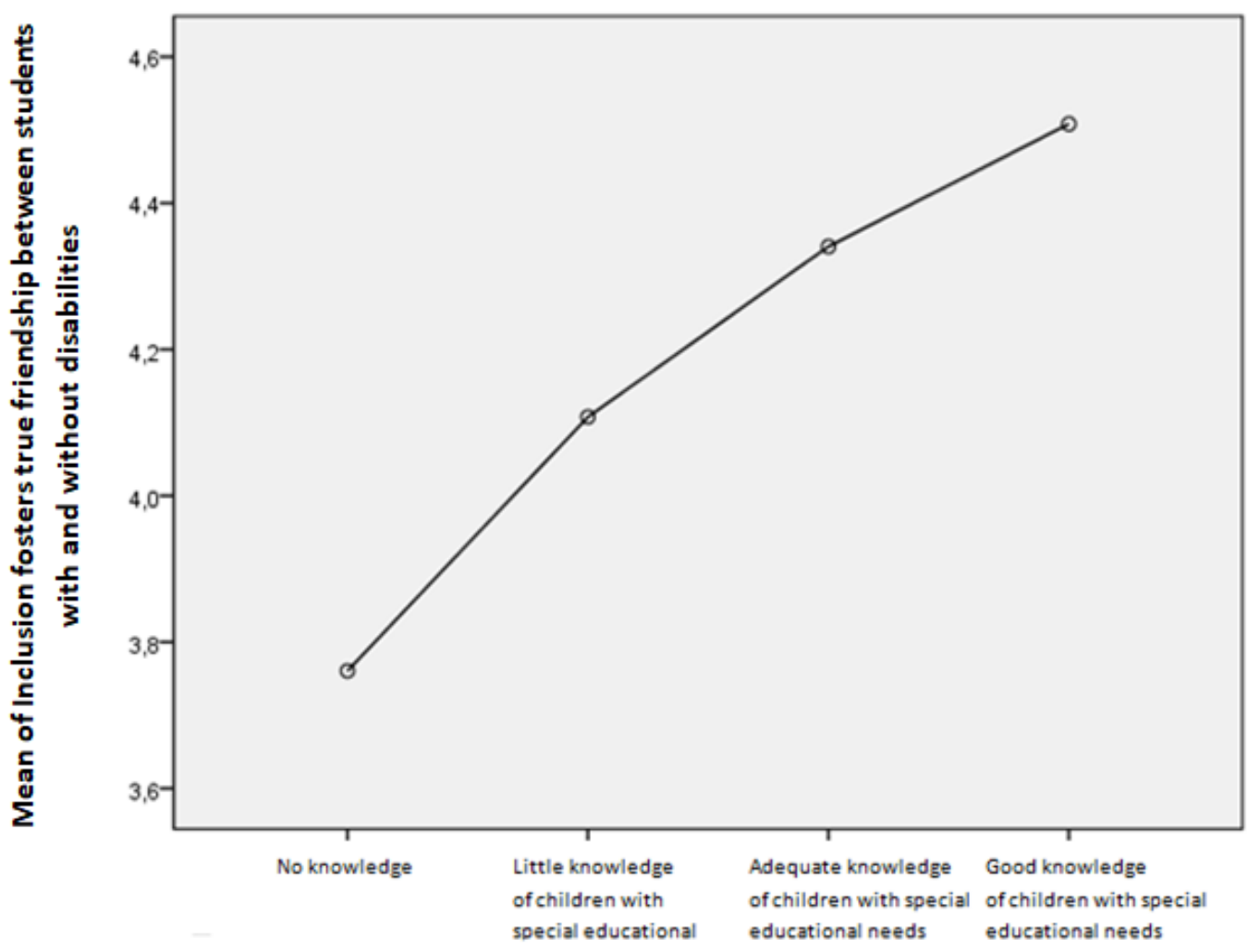

Please evaluate your knowledge in children with special educational needs on a scale of 1-5

Graph 6: Distribution of groups according to teachers' knowledge in special education: Inclusion and friendship between students.

Teachers with no knowledge (N:71, mean 4,27) and little knowledge (N:297, mean 4,29) agree that inclusion fosters friendship between students. Those with adequate $(\mathrm{N}: 91$, mean 4,56) and good knowledge (N:61, mean 4,43) strongly agree. Descriptive statistics were used for the evaluation. According to the ANOVA analysis of variance, a significant statistical deviation is observed in teachers' answers (F3,516 =3,349, $\mathrm{P}=0,019)$.

\subsection{Qualitative Aspects of Teachers' Views on Inclusive Education}

\subsubsection{Question: Please describe your views on inclusion}

When asked about inclusion, kindergarten and primary school teachers talked about successful inclusion and how this can be made possible. They believe that "the integration of children with special educational needs in the general classroom can be successful only when the necessary conditions exist: adequate building infrastructure, spaces for exercise and special activities and appropriate education staff, not only parallel support teachers but also an assistant, psychologist and physiotherapist" and that "integration is successful only through cooperation and proper training". 
Participants associate successful inclusion with structures, since "the existence of appropriate structures at the individual, educational and state level can ensure that the work done is remarkable," and with the training of teachers, as "it is necessary that certain conditions apply for inclusion to be successful, like the adequate training of teachers along with a suitably adapted school environment and curriculum". Only through the "essential training of teachers and financial upgrading of schools" can "all children be integrated into the general school".

They believe in the necessity of special education teachers and point out their important role, saying that "the inclusion of children with disabilities into the general classroom is both feasible and necessary. Equally necessary are special education teachers and support from relevant institutions". "In many cases, inclusion helps children with special educational needs, although parents are skeptical. The role of the special education teacher is valuable". A basic prerequisite are flexible analytical programmes, since "inclusion is a crucial process for the student but its effective realisation demands the existence of certain conditions like a parallel support teacher, a flexible analytical programme and much more".

Moreover, they focus on the school environment, which "needs to be aware of the problem in order for these children to be integrated smoothly in the best possible manner" and stress that "inclusion is necessary for all schools" and that "the practice of inclusion must be maintained and strengthened," as it will translate into positive outcomes for all children and "under specific conditions it can have a positive impact on children both with and without special educational needs". They recognise the importance of inclusion for the process of transition as well, since "it is necessary to properly integrate children and prepare them for their transition from the kindergarten to the primary school".

\section{Discussion}

All teachers agree and strongly agree that the children with special educational needs or disabilities should participate in activities along with their fellow students, with the exception of those teachers who have no knowledge in special education and vacillate. They are not persuaded, however, that typically developing students are ready to accept their disabled peers. The analysis of questionnaires reveals that they do not have the knowledge, skills and experience to teach in classrooms attended by both typically and non-typically developing children. Participants agree that the full inclusion of students into the general school requires cooperation between the general and special education structures and the scientific personnel. Furthermore, they believe that inclusive education fosters true friendship between the students.

Participating teachers point out the significant role of specific conditions, like building infrastructure, spaces for activities, appropriate teaching staff, psychologists and other specialists, while they associate inclusion with the training of teachers and the collaboration between the educational staff in schools. They believe that the child's environment has to be aware of its difficulties and recognise the importance of inclusion for the process of transition from kindergarten to primary school.

We speak of single education not only to express the model of parallel education of children with disabilities along with children with typical development, but also to highlight the educational philosophy that entails a single system of education (Goudiras, 2013). Singe education is the right of children with disabilities or special educational needs to participate in the school programme on equal terms and thus it is necessary for schools to be ready to accept them. 
During the basic training of candidate teachers, it is important to instill into them the ability to associate the scientific knowledge gradually acquired throughout their studies with the practice of pedagogy (Michalopoulou, 2013). Continuing training of general class teachers is an essential stage in realising inclusion (Zoniou-Sideri, 2000,2004 $\beta$ ). Teachers state that they need support in order to respond to the needs of all students in the general school (Florian and Linklater, 2010; Forlin, 2010). Continuing training in inclusion issues has to be multifaceted and well-designed.

In conclusion, the present study aims to investigate the attitude of kindergarten and primary school teachers towards inclusive education in Greece. Nevertheless, it is necessary that further studies are carried out in other regions of Greece in order to permit a wider-scale generalisation of data. We suggest that the educational intervention programme is implemented in the general classes of education in the Region of Epirus-where the study was carried out-attended by students with special educational needs or disabilities, so as to draw useful conclusions on inclusive education (a school for all).

In a future study we wish to investigate the processes considered appropriate by teachers in order to acquire knowledge in special education and to improve children's learning, as well as to determine whether teachers are familiar with methods that allow them to evaluate their performance in an inclusive classroom.

\section{References}

Ainscow, M., Conteh, J., Dyson, A., \& Gallannaugh, F. (2010). 'Children in primary education: Demography, culture, diversity, inclusion'. In R.J., Alexander, Ch., Doddington, J. Gray, L. Hargreaves, \& R. Kershner (Eds.), The Cambridge Primary Review Research Surveys. London: Routledge.

Engelbrecht, P., (2013). Teacher education for inclusion, international perspectives. European Journal of Special Needs Education, 28(2), 115-118.

Florian, L., \& Black-Hawkins, K.,( 2011). Exploring Inclusive Pedagogy. British Educational Research Journal, 37(5), 813-828.

Florian, L., \& Linklater, H. (2010). Preparing teachers for inclusive education: Using inclusive pedagogy to enhance teaching and learning for all. Cambridge Journal of Education, 40(4), 369-386.

Forlin, C. (2010). Teacher Education for Inclusion: Changing paradigms and innovative approaches.Oxford: Routledge.

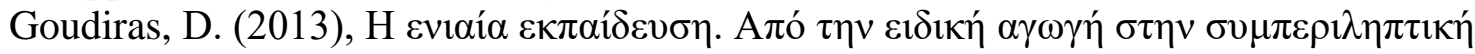

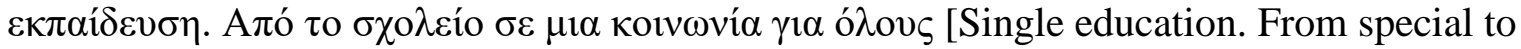
inclusive education. From an inclusive school to an inclusive society]. Grafima Publications.

Husbands, C. \& Pearce, J.(2012). What makes great pedagogy? Nine claims from research. Nottingham: National College for School Leadership.

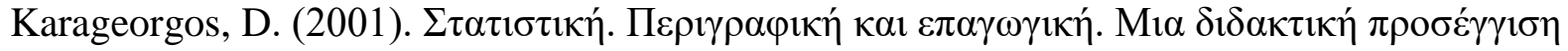
[Statistics. Descriptive and Inferential. A Teaching Approach]. Athens: Savalas.

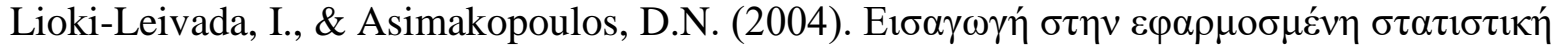
[Introduction to applied statistics]. Athens: Symmetria.

McLeskey, J., Waldron, N., \& Redd, L. (2012). A case study of a highly effective, inclusive elementary school. Journal of Special Education.

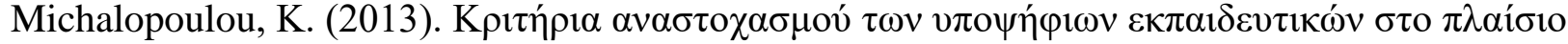

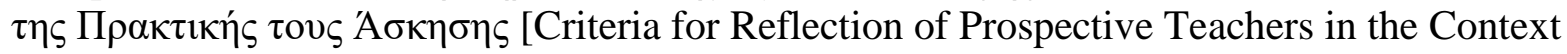




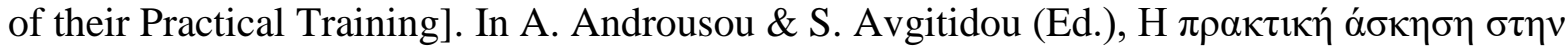
$\alpha \rho \chi \imath \kappa \eta ́ ~ \varepsilon \kappa \pi \alpha i ́ \delta \varepsilon v \sigma \eta \tau \omega v \varepsilon \kappa \pi \alpha \iota \delta \varepsilon v \tau \iota \kappa \omega ́ v: ~ E \rho \varepsilon v v \eta \tau \iota \kappa \varepsilon ́ \varsigma \pi \rho о \sigma \varepsilon \gamma \gamma i ́ \sigma \varepsilon ı \varsigma$ [Practical Training as Part of Initial Education of Teachers: Research approaches] (pp. 157-170). Department of Early Childhood Education, National and Kapodistrian University of Athens. Athens: University of Athens Internships' Network.

Law 4074/2012: Ratification of the UN Convention on the Rights of Persons with Disabilities and the Optional Protocol to the Convention on the Rights of Persons with Disabilities (Government Gazette 88/A/2012), 11-04-2012.

Norwich, B. (2000). Inclusion in education: From concepts, values, and critique to practice, in Daniels, H. (ed.). Special education re-formed. Beyond rhetoric?, (pp. 5-30). London: Routledge Falmer Press.

Rytivaara, A. \& Kershner, R., (2012). Co-teaching as a context for teachers' professional learning and joint knowledge construction. Teaching and Teacher Education, 28 (7), 9991008.

Slee, R. (2011). The irregular school: Exclusion, schooling, and inclusive education. Abbingdon, UK: Routledge.

Strati, P. (2017). Inclusion of typically- and non-typically developed children inside the general class and their transition from the Kindergarten to the Elementary School. Doctoral Thesis, University of Ioannina.

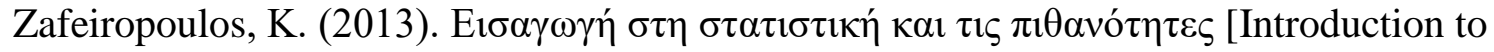
Statistics and Probability]. Athens: Kritiki.

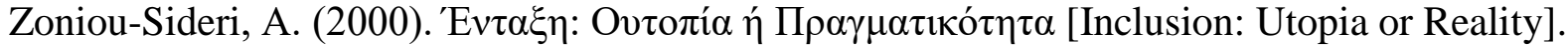
Athens: Ellinika Grammata.

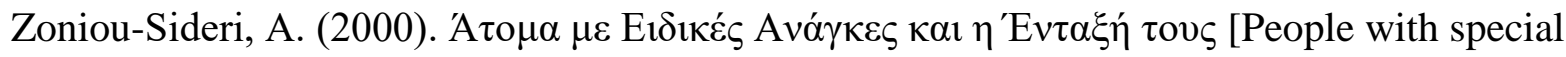
Needs and their Inclusion]. Athens: Ellinika Grammata.

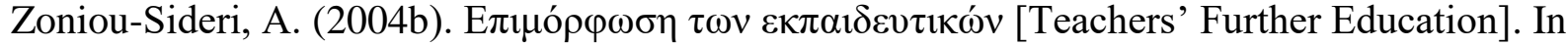

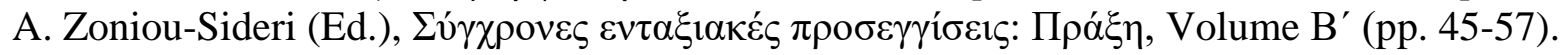
Athens: Ellinika Grammata. 